\title{
control de calidad del yeso "plasterboard"
}

\author{
quality control of gypsum "plasterboard" \\ («Gypsum Journal», n.† 16 pag. 8, enero 1960)
}

El primer yeso plasterboard producido consistía en dos capas externas de cartón sujetando un núcleo de yeso que, a su vez, contenía dos o más capas adicionales de papel, separada cada una de ellas por una delgada capa de yeso. Los pioneros del plasterboard tenían la idea completamente errónea de que esta multilaminación de papel y yeso era necesaria para producir un panel ligero de peso, flexible y que podía clavarse fácilmente; sin embargo, se apreció que cualquier intento de penetración de un clavo a través de una placa de plasterboard sólido, la fracturaba en todas las direcciones. Los modernos fabricantes de plasterboard han superado todas estas objeciones, empleando un yeso de París cuidadosamente controlado para formar un núcleo de yeso completamente celular, que se encuentra encajado sólo en dos láminas de cartón especialmente preparado.

Los pioneros habían de contentarse con producir placas hasta de $80 \times 90 \mathrm{~cm}$. Hoy día la industria británica puede ofrecer paneles hasta de $3,50 \mathrm{~m}$ de longitud, habiéndose preparado en Estados Unidos un panel de casi $5 \mathrm{~m}$ de longitud. En la tabla 1 se indican los varios tipos de plasterboard disponibles. El gran número de tamaños standard permite al constructor elegir paneles de tamaño adecuado para forrar paredes, tabiques o cielos rasos, reduciendo al máximo los recortes y al mínimo el número de juntas. Esto es particularmente importante cuando se usa el cartón de yeso como base para la decoración directa en el trabajo de construcción «seca».

El control de calidad del yeso plasterboard se efectúa para gobernar los aspectos esenciales que hacen que este material se emplee como elemento de construcción y también facilitar su trabajo tanto en la puesta en obra como en su posterior decoración. Cada fabricante tiene su propia norma de calidad; pero para cumplir los requisitos de las B. S. S., el papel debe cumplir las especificaciones señaladas en la tabla 2.

Para el ensayo de rotura con carga, la probeta (L) se corta con la dimensión más larga paralela al borde del papel que cubre el panel, y la probeta $(\mathrm{X})$ se corta normalmente a esta dirección. 


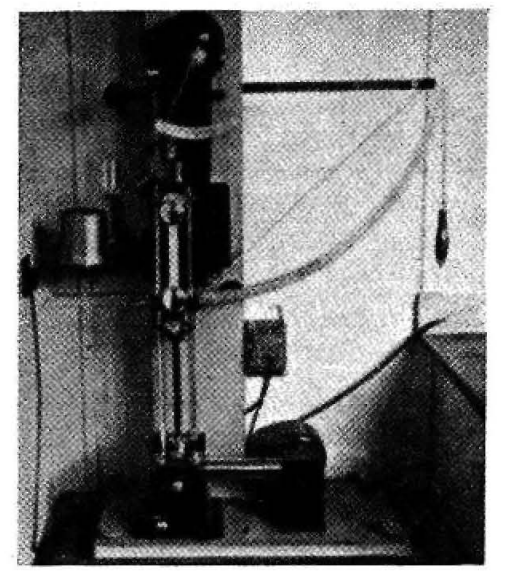

Fit. 1

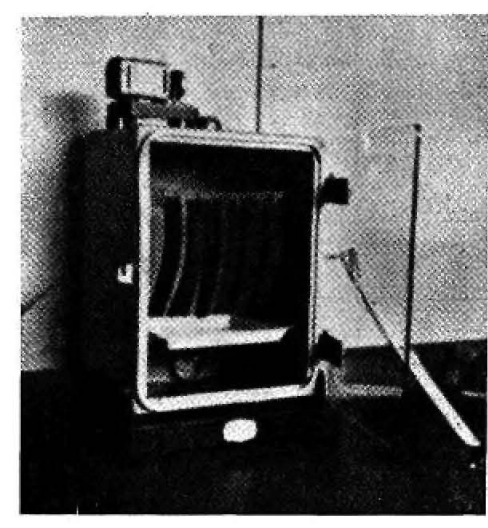

Fig. 2

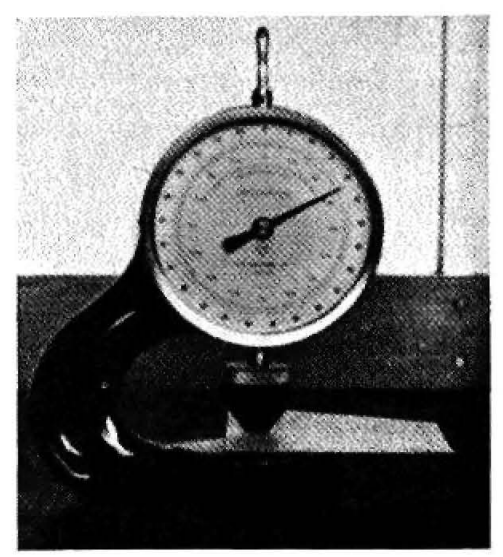

Fig. 3
Las probetas de ensayo para cartón de yeso, zócalos y tableros miden $45 \times 30 \mathrm{~cm}$ y se ensayan entre puntos situados a $40 \mathrm{~cm}$; las probetas para listones miden $40 \times 30 \mathrm{~cm}$ y se ensayan entre apoyos situados a $35 \mathrm{~cm}$. En el ensayo, cada probeta se soporta boca abajo sobre soportes paralelos en radios que oscilan desde 3 a $10 \mathrm{~mm}$ espaciados en los puntos adecuados. La carga se aplica a una velocidad de 14 a $30 \mathrm{~kg} / \mathrm{min}$ en el centro del vano a lo largo de la línea paralela al borde del soporte, a través de un apoyo redondeado con un radio de 3 a 10 milímetros.

Aunque el plasterboard puede describirse, en general, como un panel de construcción compuesto de un núcleo de yeso fraguado encajado entre dos hojas de cartón, lo más importante es la composición de estos componentes. El mineral del que se fabrica el yeso cocido se conoce como piedra de yeso, y químicamente es el dihidrato del sulfato cálcico, de fórmula $\mathrm{SO}_{4} \mathrm{Ca} \cdot 2 \mathrm{H}_{2} \mathrm{O}$. Para fabricar el plasterboard se selecciona mineral de alta calidad y debe controlarse cuidadosamente el proceso para conseguir el grado correcto de yeso de París. El plasterboard se fabrica siempre con yeso que șe encuentra en la forma de hemihidrato, $\mathrm{SO}_{4} \mathrm{Ca} .1 / 2 \mathrm{H}_{2} \mathrm{O}$. La producción creciente de plasterboard ha requerido el uso de un yeso hemihidrato de fraguado rápido, normalmente llevado a cabo por adición de pequeñas cantidades de ciertas sales metálicas al yeso hemihidrato seco.

El cartón con el que se fabrica el plasterboard exige un alto grado de destreza por parte del fabricante de papel. Para conseguir todas las propiedades que interesan y que son necesarias para su uso en la fabricación del plasterboard, el papel se fabrica de 6 ó 7 hojas fuertemente comprimidas para formar una hoja única. De esta forma, la composición de cada una de estas hojas puede controlarse cuidadosamente para dar el grado deseado de resistencia, porosidad y resistencia a la penetración del agua.

El modo en que se aplica el plasterboard, como parte integral de una construcción, exige resistencia. $\mathrm{El}$ papel es particularmente resistente en tensión, y el fabricante dedica much n tiempo a investigación para elegir el tipo correcto de papel cartón que produzca un plasterboard de máxima resistencia. A la vez, el papel que elige debe cumplir las funciones especiales necesarias para fabricar el cartón. El aspecto más esencial del papel es su resistencia a la tracción, y en la fotografía número 1 vemos una máquina típica de laboratorio para determinar esta propiedad. Las probetas de papel, que son de $2,5 \mathrm{~cm}$ de ancho por $17,5 \mathrm{~cm}$ de largo, se condicionan primero a una temperatura y humedad relativa standard en una estufa similar a la de la fotografía número 2 . Entonces, cada probeta se amordaza en la máquina y se somete a una velocidad de carga constante hasta rotura. El espesor del papel es un factor importante en su resistencia a tracción, la cual se determina por medio de un calibre, como se ve en la figura 3. 


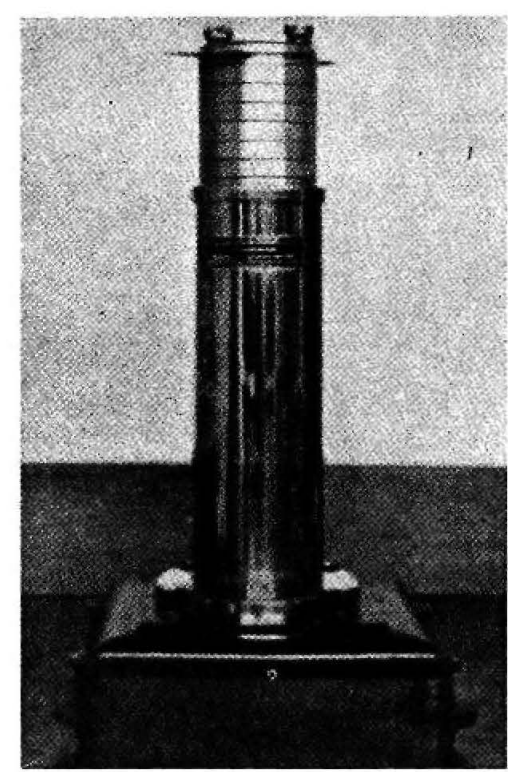

Fig. 4

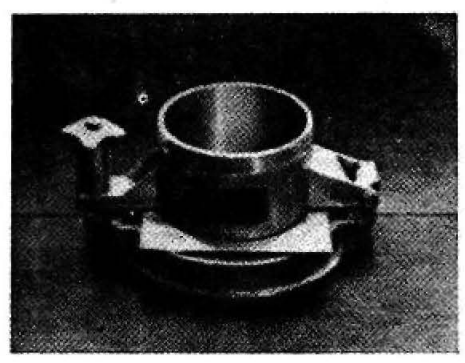

Fig. 5

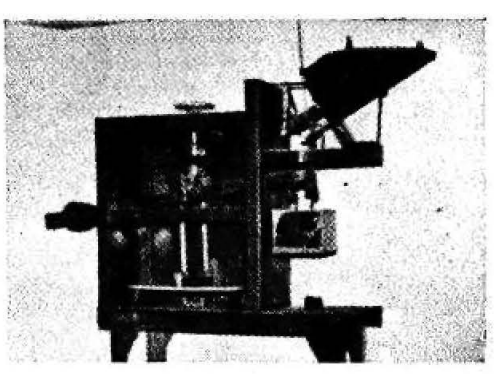

Fig. 6
El grado de porosidad del papel se mide sobre un densómetro, mediante el cual se anota el tiempo requerido para pasar 100 c.c. de aire a través de un círculo de papel de $2,50 \mathrm{~cm}$ de diámetro. Por la fotografía 4 se observa que el densómetro consiste esencialmente en un tubo cilíndrico con un orificio de $2,50 \mathrm{~cm}$ en su parte superior, encajando su parte inferior en un segundo cilindro que contiene aceite para hacer cierre hermético.

Un método para medir el grado de encolado es someter una muestra, pesada, de dimensiones dadas, a una presión de agua constante, en un tiempo determinado. El aumento de peso de la muestra dará una medida de la resistencia del papel a la penetración del agua. El instrumento de ensayo se conoce como ensayador «Cobb», siendo un ejemplo típico el de la fotografía número 5. Para suministrar el tipo ideal de papel al cual adherirá el yeso, es necesario que la resistencia a la penetración de agua del papel se encuentre entre ciertos límites. En efecto, la adherencia entre los dos materiales es más que una simple adhesión, porque, al aplicar el yeso al papel, los cristales en forma de aguja que se forman durante el fraguado penetran el papel y se «acuñan» en su estructura fibrosa, formando así una unión excepcionalmente fuerte.

Se observará en la tabla número 1 que el plasterboard se fabrica de varias longitudes, anchuras y espesores, controlando cuidadosamente cada una de estas dimensiones durante la fabricación para asegurar que el producto final se encuentra dentro de las tolerancias señaladas en la tabla número 2 .

La estructura celular del yeso fraguado en el núcleo, regula el peso del plasterboard. El fabricante, por lo tanto, presta especial atención a la molienda del mineral de yeso antes de convertirse en yeso de París, porque la extensión en que el último se mezcla rápidamente con el agua y con un agente espumante adecuado para formar un núcleo celular, depende, principalmente, del tamaño y forma de las partículas. La resistencia final del plasterboard se debe al efecto combinado del papel y el núcleo de yeso, y la contribución del último varía de acuerdo con su densidad. Por lo tanto, fabricando la mejor calidad de yeso para el núcleo del plasterboard, el fabricante debe conservar un equilibrio entre peso y resistencia. La fotografía número 6 nos muestra una máquina de laboratorio que se usa para determinar la resistencia a la rotura del plasterboard.

Además de las grandes facilidades de ensayo que existen en los laboratorios de los fabricantes de plasterboard, también operan unidades de control de calidad en varios puntos de la cadena de fabricación. A intervalos frecuentes se toman muestras de ensayo, asegurando así un buen índice de calidad en el producto terminado. 
T A B L A 1

\section{TIPS DE PIEZAS}



\begin{tabular}{|c|c|c|c|}
\hline $\begin{array}{l}\text { Longitudes } \\
\text { [m] }\end{array}$ & $\underset{(n)}{\text { Anchuras }}$ & \multicolumn{2}{|c|}{$\begin{array}{c}\text { Espesores } \\
\{m n\}\end{array}$} \\
\hline $\begin{array}{l}1,83 \\
2,13 \\
2,28 \\
2,43 \\
2,58 \\
2,74 \\
\mathbf{3 , 0 4} \\
\mathbf{3 , 3 5} \\
\mathbf{3 , 6 6}\end{array}$ & $\begin{array}{l}0,61 \\
0,91 \\
0,91 \\
1,21\end{array}$ & 9,5 & y 12,7 \\
\hline \multirow[t]{2}{*}{$\begin{array}{l}0,76 \\
0,81 \\
1,21 \\
1,36\end{array}$} & 0,91 & & 9,5 \\
\hline & $i$ & & \\
\hline $\begin{array}{l}1,06 \\
1,22 \\
1,36\end{array}$ & $0,4 \dot{0}$ & 9,5 & y $12^{r}$ \\
\hline
\end{tabular}

Plasterboard de yeso alsLantw.

Un plasterboard en forma de panel, placa o ljstón con una hoja de metal brillante de baja emistvidad en uno o ambos lados.

Ver más arriba

\section{Tablero DE YEso.}

Un plasterboard de $19 \mathrm{~mm}$ de espesor y de un ancho no superlor a $0,61 \mathrm{~m}$. Puede diseñarse para reclbir decoración directa sin aplicación previa de capa o capas de yeso y puede tener una superficle diseñada para recibir yeso.

T A B L A 2

\begin{tabular}{|c|c|c|c|c|c|c|c|}
\hline & Toler & ncias dim & ngionales & Peso e & $\mathbf{k g} / \mathbf{m}^{3}$ & $\begin{array}{c}\text { Carga } \\
\text { rotura }\end{array}$ & $\begin{array}{l}\text { inimat de } \\
\text { en } \mathbf{~ k g}\end{array}$ \\
\hline & Longltud & Aluohurs & Eapesor & Minime & Máximo & Direcel6n & $\underset{x}{\text { Diresel } 6 n}$ \\
\hline Placas de yeso. & $\begin{array}{r}+0 \\
-6\end{array}$ & $\begin{array}{r}+3 \\
-3\end{array}$ & $9,50 \pm 0,5$ & 6,83 & 9,76 & 15,8 & $\begin{array}{l}11,3 \\
:\end{array}$ \\
\hline Listones de yeso. & $\begin{array}{l}+0 \\
-6\end{array}$ & $\begin{array}{l}+3 \\
-3\end{array}$ & $\begin{array}{r}9,50 \pm 0,5 \\
12,70 \pm 0,6\end{array}$ & $\begin{array}{l}6,83 \\
9,27\end{array}$ & $\begin{array}{r}9,76 \\
14,64\end{array}$ & $\frac{18,1}{-}$ & $\begin{array}{c}12,7 \\
-\end{array}$ \\
\hline Paneles de yeso. & $\begin{array}{l}+0 \\
-6\end{array}$ & $\begin{array}{l}+0 \\
-4,7\end{array}$ & $\begin{array}{r}9,50 \pm 0,5 \\
12,70 \pm 0,6\end{array}$ & $\begin{array}{l}6,83 \\
9,27\end{array}$ & $\begin{array}{r}9,76 \\
14,64\end{array}$ & $\begin{array}{l}36,2 \\
47,6\end{array}$ & $\begin{array}{l}15,4 \\
20,4\end{array}$ \\
\hline Tableros de yeso. & $\begin{array}{l}+0 \\
-9,5\end{array}$ & $\begin{array}{l}+3 \\
-3\end{array}$ & $19,05 \pm 0,7$ & 14,16 & 20,50 & 68,0 & 27,2 \\
\hline
\end{tabular}

